\title{
LECTURAS TEOLÓGICAS DEL HUMANISTA JUAN FUNGUERIO: UNA MIRADA A TRAVÉS DE SU BIBLIOTECA
}

\section{THEOLOGICAL READINGS OF THE HUMANIST JUAN FUNGUERIO: A LOOK THROUGH HIS LIBRARY}

\author{
BEATRIZ COMELLA-GUTIÉRREZ \\ Universidad Nacional de Educación a Distancia
}

Recibido: 07/06/2021 Aceptado: 22/09/2021

\section{RESUMEN}

El presente trabajo tiene como objetivo dar a conocer la biblioteca teológica del humanista neerlandés Juan Funguerio (1546-1612), comprobando si sus lecturas reflejan su personalidad y contexto; formado en las universidades católicas de Lovaina y Colonia, ejerció como director de escuelas de gramática latina en su Frisia natal y se adhirió tempranamente al calvinismo moderado. Cuatro son los enfoques metodológicos utilizados: histórico, cuantitativo, cualitativo y hermenéutico, partiendo del catálogo de la subasta de su biblioteca, ejecutada en Leiden al año siguiente de su muerte. Es patente su aprecio por la Sagrada Escritura, los Padres de la Iglesia y los autores coetáneos reformados.

Palabras clave: Biblioteca privada, calvinismo moderado, Juan Funguerio, Humanismo, Teología.

\section{ABSTRACT}

The present work aims to present the theological library of the Dutch humanist Juan Funguerio (1546-1612), checking if his readings reflect his personality and context; 
Trained at the Catholic universities of Louvain and Cologne, he served as director of Latin grammar schools in his native Friesland and early adhered to moderate Calvinism. There are four methodological approaches used: historical, quantitative, qualitative and hermeneutical, based on the catalog of his library auction, carried out in Leiden the year after his death. His appreciation of Sacred Scripture, the Church Fathers, and contemporary Reformed authors is evident.

Keywords: Iohannes Funguerius, Humanism, moderate Calvinism, Private Library, Theology.

\section{INTRODUCCIÓN}

El presente artículo sigue una de las líneas de investigación del Grupo de Estudios Medievales y Renacentistas (GEMYR), dirigido por el Profesor Javier Vergara Ciordia, en la Facultad de Educación de la Universidad Nacional de Educación a Distancia (UNED). Responde al firme deseo de contribuir, desde la investigación y la reflexión, a recuperar el sentido humanista de la cultura, como aportación al mundo actual, mediante la traducción y difusión de fuentes medievales y renacentistas, inéditas o apenas conocidas, que han contribuido a conformar el pensamiento europeo occidental, en el plano de la educación y de la cultura ${ }^{1}$. En consonancia con todo ello, la autora ha realizado trabajos académicos previos, acerca de la figura, contexto y obra escrita del humanista neerlandés Juan Funguerio (Johannes Fungerius) (1546-1612) ${ }^{2}$, doctor en ambos Derechos, pedagogo, profesor de latinidad y bibliófilo que, sin ocupar un lugar de primera fila entre los hombres de letras de su tiempo, es un representante neto del humanismo del norte de Europa y, en concreto, de los Países Bajos, durante unas décadas en que se modificaron las fronteras políticas y religiosas de su entorno. Hasta el momento, se ha estudiado de modo especial, mediante el análisis de su obra escrita, su pensamiento filosófico y teológico, educativo y político, así como su biblioteca y, en particular, los libros de la Sagrada Escritura de

1 Proyecto Difusión del Patrimonio pedagógico occidental (siglos XIV-XVIII). Digitalización, traducción y estudio de fuentes inéditas del humanismo. MINECO EDU2016-79080-R (2016-2019).

2 El nombre latino de Johannes Funguerius aparece en sus obras, en las fuentes y bibliografía sobre él con diversas variantes, por ese motivo, nos referiremos a él como Juan Funguerio, con su nombre más frecuente castellanizado. A lo largo del trabajo, se ha intentado mantener un único criterio en los nombres y apellidos de los autores citados, otorgando prevalencia al latino, aunque, en ocasiones, se emplea el más conocido en su propia lengua vernácula. 
su propiedad ${ }^{3}$. También se ha abordado la relación de su obra con la censura, tanto romana como hispana, que fue relativamente escasa ${ }^{4}$.

Mediante el presente trabajo, se pretende describir, analizar e interpretar los demás títulos de temática teológica, a fin de comprobar si responden a la personalidad y circunstancias vitales de su dueño: un calvinista moderado neerlandés de primera hora, que había sido alumno de universidades católicas, testigo de la independencia de las Provincias Unidas de los Países Bajos y de la fragmentación religiosa de Centroeuropa, durante el reinado de Felipe II.

Desde el punto de vista metodológico, el documento marco de esta investigación es el catálogo de subasta de la citada biblioteca, publicado en Leiden en 1613, al año siguiente del fallecimiento de su dueño ${ }^{5}$. Cuatro son los enfoques para su estudio: el histórico, a fin de situar a Juan Funguerio en su contexto vital y cultural; el cuantitativo, para trazar el mapa general de una biblioteca privada notable como la suya, integrada por 1155 títulos $^{6}$; el cualitativo, a fin de analizar

3 Juan Funger, Libro sobre la buena enseñanza y educación de los jóvenes (1584) De puerorum disciplina et recta educatione liber. Beatriz Comella-Gutiérrez, Estudio preliminar. Virgilio Rodríguez García, Traducción y notas (Madrid: UNED-BAC, 2018); Beatriz Comella-Gutiérrez, "El humanista neerlandés Juan Funguerio (1546-1612): de la teoría a la práctica política”. En Estudios de educación política, coordinado por Javier Vergara Ciordia-Alicia Sala Villaverde (Madrid: Dykinson, 2019), 251260; "Johann Funger's pedagogy in the context of northern humanism", History of Education\& Children's Literature, XIII/1 (2018): 355-374; "La Sagrada Escritura en la biblioteca de Juan Funguerio (1546-1612), un calvinista neerlandés de primera hora", Anuario de Historia de la Iglesia 29 (2020): 375-403 doi:10.15581/007.29.003..

4 Beatriz Comella-Gutiérrez, "El humanista Juan Funguerio ante la censura". En Censura y libros en la Edad Moderna, coordinador por Javier Vergara Ciordia-Alicia Sala Villaverde (Madrid: Dykinson, 2017), 269 - 281.

5 Veilingcatalogus bibliotheek Johannes Fungeri, 1613 (Catálogo de la subasta de la biblioteca de Juan Funguerio). Un ejemplar del catálogo original se encuentra en la Köngelige Bibliotek Kopenhagen (Biblioteca Nacional de Dinamarca), con la referencia ms. 79 II 29. Martin H. Engels, antiguo curator de la Provinciale Bibliotheek van Friesland (Biblioteca Provincial de Frisia en Leeuwarden) ha publicado una base de datos basada en dicho catálogo: http://www.mpaginae.nl/ (Consultada 22-122020). Este documento ha sido esencial para nuestro estudio.

6 En el siglo XVI, las mayores colecciones privadas de libros pertenecían a los reyes y a los miembros de la alta nobleza civil y religiosa, algunas con más de mil obras. Con un volumen semejante se hallaban los estaban los mercaderes y la aristocracia del dinero. Seguían después los médicos y los hombres de carrera política y administrativa, cuyas bibliotecas podían alcanzar el medio millar de volúmenes, en su mayoría de carácter profesional. Las bibliotecas de otros colectivos, como profesores, artistas y artesanos, podían oscilar entre la quincena y el centenar de libros. De todas las maneras, hay que advertir que no todos los que pertenecían a estos grupos poseían libros. Juan Carlos Galende Díaz, "Las bibliotecas de los humanistas y el Renacimiento", en Revista general de información y documentación, 6 (1996/2): 25 y Vicente Becares Botas, "Los libros y las lecturas del humanista", en Silva: Estudios de humanismo y tradición clásica, 2 (2003): 23-40. Un ejemplo de este último tipo de bibliotecas es el estudio ya clásico, de Antonio R. Rodríguez Moñino, La biblioteca de Benito Arias Montano. Noticias y documentos para su reconstrucción (1548-1598) (Badajoz: Diputación Provincial de Badajoz,1929). 
la tipología de los mismos y, finalmente, el hermenéutico, que aportará cierta interpretación sobre las lecturas de acuerdo con las coordenadas espacio-temporales y culturales de su dueño, puesto que, siguiendo al hispanista británico Trevor J. Dadson, "los libros no existen en el vacío; pertenecen a ciertos individuos en determinados momentos de la historia. Si queremos entender la importancia de aquéllos, tenemos que saber más acerca de éstos"7.

Esta cuádruple metodología se aplicará con detalle a los libros teológicos del humanista neerlandés: se tendrá en cuenta la proporción de dicha temática respecto al conjunto de los libros de su propiedad; se clasificarán por tamaño, según el sistema empleado en las bibliotecas de entonces; se aplicará el criterio de autoría y cronología; se analizará la temática, de acuerdo con las ramas o disciplinas teológicas, señalando los porcentajes sobre el total; se señalarán las plazas de impresión y los editores más habituales; se buscarán las autorías más frecuentes y el tipo de libros que interesaron a Juan Funguerio, infiriendo posteriormente las principales conclusiones. Previamente, como se ha indicado, se trazarán algunos rasgos biográficos y una somera exposición de la situación política y religiosa de los Países Bajos, a partir de la segunda mitad del siglo XVI, para contextualizar el estudio de la citada biblioteca y de su dueño.

\section{JUAN FUNGUERIO: EL HUMANISTA EN SU CONTEXTO POLÍTICO- RELIGIOSO}

No son abundantes los datos sobre la vida de Juan Funguerio, pero sí suficientes para justipreciar su biblioteca privada. Es seguro que nació en 1546, año de la muerte de Lutero; fue, por tanto, coetáneo de Bucero, Melanchthon, Calvino, Bullinger y Sturm ${ }^{8}$. Recibió el mismo nombre de pila de su padre, que fue director o rector de la escuela de gramática latina en su ciudad natal, Leeuwarden, capital de Frisia ${ }^{9}$. A buen seguro, su entorno familiar introdujo al joven Funguerio en el espíritu del humanismo. Se casó con Lucrecia Wybes, hija de Wybrand van Hallum, también latinista y rector de la escuela de gramática. Es decir, siguió profesionalmente a su padre y a su suegro ${ }^{10}$. Después de la

7 Trevor J. Dadson, Libros, lectores y lecturas, estudios sobre bibliotecas particulares españolas del Siglo de Oro (Madrid: Arco Libros, 1998), 48.

8 Murieron respectivamente en 1551, 1560, 1564, 1575 y 1589.

9 Sobre las escuelas de gramática o de latinidad del humanismo, José Luis Paradinas Fuentes, Humanismo y educación en el Dictatum Christianum de Benito Arias Montano (Huelva: Publicaciones de la Universidad de Huelva, 2006), 154-156.

10 Philipp Ch. Molhuysen-Petrus J. Blok, Nieuw Nederlandschbiografisch woordenboek, (Leiden: A.W. Sijthoff, 1918), 625. 
educación preparatoria, posiblemente en la escuela paterna, Juan Funguerio fue alumno de dos Universidades de tradición católica: Lovaina (Colegio Trilingüe) y Colonia ${ }^{11}$. Allí estudió Artes liberales, lenguas bíblicas, medicina, derecho civil y canónico, carrera de la que obtuvo el grado de doctor.

Parece que Funguerio también viajó por otras ciudades como Amberes y Leiden (Países Bajos), Frankfurt (Alemania) y Lyon (Francia), donde fueron publicadas sus principales obras. Sin embargo, teniendo en cuenta los datos conocidos, su amplia obra en latín y la temática de ésta, su vocación fundamental consistió en ser un humanista, aunque se dedicara ocasionalmente a la judicatura; de hecho, el 11 marzo de 1579 se dio de alta en la corporación de abogados de Frisia y ejerció como jurisconsulto en la Corte de Justicia ${ }^{12}$. Dos años más tarde, se produjo la independencia de las siete Provincias Unidas del norte de los Países Bajos, respecto a Felipe II, bajo el liderazgo del líder calvinista Guillermo de Orange-Nassau. Frisia se unió a este proyecto político-religioso sin ambages.

Se sabe, no obstante, que en 1584 Juan Funguerio dio un giro a su vida profesional: desde entonces su ocupación principal fue ser rector de escuelas de gramática en Frisia; para ejercer dicho cargo, era preciso pertenecer a la congregación calvinista local, si bien, como veremos a través del estudio de su biblioteca, fue un hombre de convicciones moderadas. Sus primeros destinos fueron Bolsward y posiblemente Groninga. En 1588, pasó a regentar la escuela de Leeuwarden, su ciudad natal, tomando postura a favor de los Orange-Nassau y la independencia ${ }^{13}$. Entre 1607 y 1612, marchó a la escuela de gramática de Franeker, donde ya se había fundado una Universidad.

11 Samme Zijlstra, Het geleerde Friesland studenten ca. 1380-1650, en:

http://files.mpaginae.webnode.com/200000728-b6ac7b7a64/FrieseStudentenvoor1650.pdf (consultado 15-5-2021).

La Universidad de Colonia fue fundada en 1388; es la cuarta más antigua del Imperio germánico: la primera fue iniciada en 1346 por Carlos IV, rey de Bohemia en Praga y estaba dividida en cuatro naciones: bávara, sajona, polaca y checa. Fue fundada para la educación superior de los estudiantes centroeuropeos que abandonaron la Universidad de París tras el inicio del cisma de Occidente de 1384. Se ha dicho que, si la Universidad de Colonia es hija de la de París, la primera es madre de la de Lovaina. Le siguieron Viena (1365), Heidelberg (1386), la citada de Colonia y Erfurt (1392). Durante el siglo XV aparecieron once más, entre ellas, la de Lovaina (1425). Su embrión fue el Colegio Trilingüe de estudios bíblicos fundado en 1517 por Jerónimo de Busleiden, siguiendo algunas pautas dadas por Erasmo de Róterdam. James Bowen, Historia de la educación occidental, vol. 2. (Barcelona: Herder, 1986), 547.

12 Martin H. Engels, Chronologische en alfabetische naamlijst 1577-1849, (Leeuwarden: Fryske Akademy, 2016).

13 Efectivamente, durante esos años, parece claro que se decantó por la independencia de Frisia y otras provincias del norte de los Países Bajos. De hecho, en 1595 publicó un panegírico dedicado al 
Se han podido localizar un total de dieciséis obras suyas, todas ellas escritas en latín, lingua franca de los humanistas europeos; en alguna de ellas, un estudio de etimología comparada, la lengua de los romanos se une al griego y hebreo. Otras contaron con el mecenazgo de notables familias de la nobleza terrateniente de Frisia. Se expresó tanto en prosa (sobre educación, ética, filología, léxico y etimología); como en verso (recopilaciones de proverbios clásicos, odas sobre próceres y hombres ilustres coetáneos, poesía sacra y moralizante). En definitiva, por lo que se refiere al contenido, los géneros literarios de sus libros se corresponden especialmente con sus estudios universitarios en el Colegio Trilingüe y, en menor, medida con su doctorado en ambos derechos.

Su labor docente e intelectual fue reconocida en vida: el 4 de junio de 1607 aparece citado en el Album studiosorum la Universidad de Franeker. Murió el 11 de mayo 1612, a los 66 años, y fue enterrado en la iglesia de San Martín de dicha ciudad. Como se ha indicado, un año después de su muerte, su rica biblioteca, de la que se conserva el catálogo, fue subastada en Leiden.

Desde el inicio de su ejercicio profesional, Juan Funguerio vivió en una de las zonas más conflictivas de Centroeuropa desde el punto de vista cultural, religioso y político. Culturalmente, el humanismo del norte de Europa hizo especial hincapié en temas relacionados con la religión y la piedad personal; posee unas características propias: en primer término un modelo antropológico basado el hombre interior que busca la relación directa del individuo con Dios, sin mediaciones eclesiales; en segundo lugar, la asimilación de la cultura grecolatina por influencia italiana desde el punto de vista lingüístico y ético; en tercer lugar, un notable interés de los eruditos por las lenguas hebrea, griega y latina para los estudios bíblicos; en cuarto lugar, el desarrollo de tratados educativos y propuesta de reformas para los studia humanitatis y la educación universitaria; en quinto lugar, abundancia de literatura sobre educación cívica y pacifismo; por último, el criticismo y las subsiguientes polémicas intelectuales y teológicas ${ }^{14}$.

Príncipe Mauricio de Orange-Nassau (1567-1625), hijo y heredero de Guillermo como estatúder de las Provincias Unidas y a Guillermo Luis de Nassau-Dillenburg (1560-1620), estatúder de Frisia, Groninga y Drente, primo de Mauricio.

14 Marcus De Schepper, Bibliographie de l'humanisme des anciens Pays-Bas: avec un répertoire bibliographique des humanistes et poètes néo-latins: supplément 1970-1985 (Bruxelles: Koninklijke Academievoor Wetenschappen Letteren en Schone Kunsten van België, 1988) y Federation Internationale des Societès et Instituts pour 1'Etude de la Renaissance, Bibliografie de l'Humanisme et la Renaissance (1965-2009) (Genève: Librairie Droz, 2010). En la actualidad, es necesario consultar los repertorios actualizados localizables a través de la red. En continuidad con las publicaciones de Droz, puede consultarse: http://blog.history.ac.uk/2014/02/international-bibliography-of-humanism-and-the-renaissa nce-seeks-contributors/ 
Desde el punto de vista religioso, se puede afirmar que el mapa de las confesiones cristianas en los Países Bajos durante el siglo XVI depende de numerosas variables, puesto que la difusión de las nuevas doctrinas no fue uniforme ${ }^{15}$. En líneas generales, es posible aseverar que hacia 1520, fecha de la excomunión de Lutero, en Frisia y el resto de las provincias del norte de los Países Bajos hispanos, se había producido una lenta pero progresiva penetración clandestina de diversas ramas de la reforma ${ }^{16}$. A partir de 1530 , se extendió de modo incipiente la reforma helvética de Zwinglio y la anabaptista de Menno Simons, esta última perseguida tanto por reformados como por católicos; a partir de 1550, la infiltración del calvinismo fue un hecho, debido en parte a la acción del humanista de origen polaco Juan Lasco, discípulo de Erasmo, marcado teológicamente por Zwinglio, Bucero y Calvino ${ }^{17}$. En cualquier caso, es necesario subrayar que en esta zona de Europa existía un caldo de cultivo propicio a partir de la expansión de la devotio moderna, el criticismo del propio Erasmo y la traducción de la Biblia a lenguas vernáculas ${ }^{18}$.

Por lo que se refiere a la actual de Frisia y otras provincias del norte, las medidas contra el avance de la reforma, por parte de las autoridades hispanas, se materializaron en la prohibición de libros de autores reformados y en la ejecución de algunos protestantes neerlandeses, entre 1525 y 1531. Por entonces, se prohibió también a los laicos predicar o hablar en público sobre la Biblia. La presión de la política religiosa produjo el exilio de neerlandeses no católicos hacia ciudades como Emden, Aquisgrán, Wesel, Frankfurt y Londres.

15 Herman Selderhuis, Handbook of Dutch Chruch History, (Göttingen: Vandenhoeck \& Ruprecht Verlage 2014), 201-223.

16 Thomas Martin Lindsay, La Reforma y su desarrollo social, (Barcelona: Clío, 1986), 135. No obstante, también eran oriundos de Frisia notables católicos como Pietersz Sjoerd (Petrus Suffridus), jurista, filólogo e historiador 1527-1597), profesor de la Universidad de Colonia; el humanista y diplomático Viglius van Aytta (1507-1577) y Joachim Hoppers (1523-1576) ambos juristas y asesores de Felipe II, que se mantuvieron fieles a Roma.

17 Vergara Ciordia, Javier, "Las obras pedagógicas del humanismo erasmista" en Peña González, Miguel Anxo - Delgado Jara, Inmaculada (coords.), Revolución en el humanismo cristiano: La edición de Erasmo del Nuevo Testamento (1516), Salamanca, 2016.

18 En el caso de los Países Bajos, Jacob van Liesvelt (ca.1489-1545) hijo de impresor Adriaen van Liesvelt, nacido en Amberes, continuó el trabajo de su padre y se dedicó a imprimir libros de autores católicos y reformados. De sus prensas salió en 1526 la primera Biblia traducida al neerlandés a partir del texto luterano. Fue acusado de comportamiento herético y decapitado en 1545. Juan Funguerio poseía dos versiones de libros bíblicos en lenguas vernáculas: un ejemplar de la Biblia neerlandesa (Een Duitschen Bijbel) publicada en Dordrecht en 1591 y un Nouveau Testament editado en La Rochelle (Francia) el mismo año, ambos libros in octavo. Paul F. Grendler, Renassaince Education between Religion and Politics, (Aldershot: Routledge 2006), 75-79. 
La evolución religiosa en los Países Bajos está directamente relacionada, como es bien conocido, por la revuelta de una parte de los neerlandeses, guiados por el príncipe calvinista Guillermo de Orange-Nassau, contra la corona española, convirtiéndose en una república independiente de las Provincias Unidas en $1581^{19}$; mientras que la actual Bélgica, Luxemburgo y territorios franceses, se mantuvieron fieles a Felipe II y la obediencia a Roma ${ }^{20}$. Los intentos diplomáticos previos de Orange ante la corte de Madrid, a fin de conseguir la misma tolerancia religiosa que gozaba el imperio germano desde la Paz de Augsburgo (1555), habían resultado fallidos; el hijo de Carlos V no podía aceptar que una parte de sus súbditos siguieran el camino de la herejía, ni a perder influencia política y económica sobre un territorio tan geoestratégico y rico como Flandes.

Uno de los puntos de inflexión del enfrentamiento tuvo lugar en 1579; las provincias del sur firmaron la Unión de Arrás reconociendo a Felipe II como soberano y, por su parte, las provincias del norte suscribieron la Unión de Utrecht, origen de la República de las Provincias Unidas, liderada por el príncipe Guillermo de Orange-Nassau y su hermano Juan VI de Nassau-Dillenburg, que fueron declarados fuera de la ley por las autoridades españolas ${ }^{21}$. La respuesta no se hizo esperar: los Estados Generales eliminaron las diócesis católicas y la falta de sacerdotes, sobre todo en zonas rurales, facilitó la agonía de los seguidores papistas. Felipe II, por su parte, había puesto precio a la cabeza de Guillermo de Orange, que fue asesinado en 1584 por Baltasar Gérard, un francés católico. Sin embargo, como es sabido, los enfrentamientos armados entre neerlandeses y españoles persistieron hasta la firma de la paz de Münster en $1648^{22}$.

19 Carlos V apadrinó a Guillermo de Orange-Nassau (1533-1584), nacido en tierra germana y educado en la fe luterana. Al heredar el título francés de príncipe de Orange con sólo once años, por la muerte sin descendencia su primo Renato de Châlon, el emperador actuó como regente y lo envió a la corte de Bruselas proporcionándole una excelente formación militar, diplomática e instrucción en la fe católica. Guillermo se adhirió al calvinismo en 1573, tras la matanza de hugonotes franceses en la desgraciada noche de san Bartolomé.

20 La independencia de la República de las Provincias Unidas de los Países Bajos, liderada por Guillermo de Orange-Nassau, aunó inicialmente a las provincias del norte como Frisia, Groninga, Holanda, Zelanda, Drenthe, Overijssel, Güeldres, ducado de Brabante, condado de Flandes y obispado de Utrecht. El resto de los territorios, situados al sur, se mantuvieron bajo la corona española (provincias de Namur, Limburgo y Luxemburgo, condado de Henao, y los territorios franceses de Artois y Douai).

21 Felipe II emitió un edicto de proscripción contra Guillermo de Orange acusándole de traición, herejía y ofreciendo una notable recompensa para quien lo entregase o asesinase. En respuesta, Guillermo publicó la Apología del príncipe de Orange justificando su carrera política y vida privada. El documento fue presentado en los Estados Generales de los Países Bajos y remitido a las cortes europeas.

22 Mauricio Ebben, El final de la Guerra de Flandes, (Madrid: Fundación Carlos de Amberes, 1998), 42-44. 


\section{LOS INTERESES DEL BIBLIÓFILO JUAN FUNGUERIO}

Teniendo en cuenta la biografía y el contexto político-religioso del humanista Funguerio, cabe preguntarse hasta qué punto su biblioteca privada refleja los avatares de su vida, sus estudios y las controversias religioso-culturales de su época. Como se ha indicado, la fuente primaria para estudio de la biblioteca fungueriana es el catálogo de la subasta pública de sus fondos, realizada en Leiden el 22 de mayo de 1613, por el librero Juan Olers de Leiden e impreso previamente en la misma ciudad por Enrique Luis de Haestens, en cuarto de folio, con un total de ochenta páginas ${ }^{23}$.

Aunque desconocemos si Juan Funguerio y su esposa Lucrecia tuvieron hijos (no hay noticias sobre este particular) parece que, si los hubo, ninguno se dedicó a la enseñanza en escuelas de latinidad (como su padre o sus abuelos) ni a la judicatura (como su padre). Esta circunstancia puede explicar que su biblioteca privada fuera subastada poco después de su fallecimiento. Otra posibilidad, es que no tuvieran descendencia, y su viuda pudiera vivir de las rentas tras la subasta, práctica frecuente en ciudades universitarias de la zona, como Lovaina y Leiden ${ }^{24}$.

Desde el punto de vista estadístico, partiendo de la base de datos publicada en la red por Martin H. Engels, curator de la Biblioteca Provincial de Frisia en Leeuwarden, y tomando como criterio la temática, el número y porcentaje de los libros la división es como sigue ${ }^{25}$ :

Tabla 1

\begin{tabular}{|c|c|c|}
\hline Temática & Número de títulos & Porcentaje \\
\hline Teología & 208 & 18,09 \\
\hline Derecho & 77 & 6,66 \\
\hline Política & 27 & 2,33 \\
\hline Medicina & 106 & 9,17 \\
\hline Quadrivium & 34 & 2,94 \\
\hline $\begin{array}{c}\text { Historia, Poesía, } \\
\text { Filosofía y Lógica }\end{array}$ & 280 & 24,28 \\
\hline
\end{tabular}

23 Cathalogvs Bibliothecae Instructissimae Doctissimi \& Viri D. Ioannis Fungeri, I.V. Doct. \& Gymnasii Franekerani Moderatoris, quae auctione distrahetur in Officina Ioannis Orlers Bibliopolae, in vico de S. Pieters Chom-Steegh. Lvgdvni Batavorvm 22 may. Anno 1613. Stylo Nouo. Excudebat Henricus Ludouici ab Haestens.

24 David McKitterick, The Invention of Rare Books: Private Interest and Public Memory (1600 1840), (Cambridge: Cambridge University Press, 2018), 336.

25 Las tablas son de elaboración propia. 


\begin{tabular}{|c|c|c|}
\hline Filología & 256 & 22,16 \\
\hline Miscelánea & 167 & 14,46 \\
\hline Total & 1155 & $100 \%$ \\
\hline
\end{tabular}

Cabe también plantearse cómo pudo adquirir una biblioteca de estas dimensiones e índole cualitativa un director de escuela de latinidad de la remota Fri$\mathrm{sia}^{26}$. Como hipótesis, es factible que llegaran a él por varias vías: donación o herencia de su padre y de su suegro; regalos de sus mecenas; pago en especie por sus propias obras; obsequios de sus editores; remuneración como corrector de pruebas de imprenta de libros que exigían conocer, además del latín, griego y hebreo; adquisiciones propias. Asimismo, es necesario subrayar que Funguerio nació, estudió y trabajó en una de las zonas de Europa con mayor número de imprentas ${ }^{27}$. Posiblemente por ese motivo, en su biblioteca privada se encontraban cuatro incunables de autores que unen la tradición grecolatina con el humanismo: Aristóteles comentado por Averroes, Salustio, Boecio y Marsilio Ficino.

\section{LAS LECTURAS TEOLÓGICAS DE JUAN FUNGUERIO}

\section{ANÁLISIS CUANTITATIVO DE LA BIBLIOTECA TEOLÓGICA FUNGUERIANA}

Se ha podido comprobar que Juan Funguerio poseía 208 títulos sobre temas teológicos, que equivalen al 18,09 \% del total de su biblioteca. En relación al tamaño, que era un modo de habitual por entonces de realizar un listado de libros, los teológicos se agrupaban en: 48 in folio, 46 in quarto, 93 in octavo y 21 in decimosexto. Respecto al año de publicación de estos títulos, solo hay uno anterior a 1520 y es el Policratus de Juan de Salisbury, salido del taller parisino de

26 Llama la atención el volumen del catálogo de la subasta integrado por 80 páginas, sobre todo si se compara con documentos semejantes coetáneos: es el caso de Johannes Drusius, un notable teólogo arminiano, al que nos referiremos más adelante, cuya biblioteca fue subastada el 26 de agosto de 1616 en Franeker; su catálogo, impreso por Fredericus Heynuis, consta de 37 páginas y puede consultarse en formato digital en: Bibliotheca Drusiana 1616.

27 Se calcula que en Europa se imprimieron hasta 1501 unos 30.000 títulos con una tirada de 20 millones de ejemplares: el 37\% en Italia, el 33\% en regiones alemanas, el 17\% en Francia, el 7\% en los Países Bajos y el 6\% en otros. Por entonces había unas 1700 imprentas en 300 ciudades. Las más antiguas de los antiguos Países Bajos se instalaron en torno a 1470 en Utrecht, Delft, Gouda, Deventer, Zwolle, Aalst, Lovaina, Brujas y Bruselas. En la década de 1480-1490 inician su trabajo las de Haarlem, Leiden, Hertogenbosch, Amberes y Gante. http://www.bibliopolis.nl/ (consultada 28-4-2021). Bibliopolis Website van de Koninklijke Bibliotheek te Den Haag over de geschiedenis van de boekdrukkunst in Nederland (Página Web de la Biblioteca Real de La Haya sobre la historia de la imprenta en los Países Bajos). En dicha Biblioteca se conservan 2000 incunables. 
Nugis en 1513; hay cinco libros sin año de edición y los 202 restantes fueron publicados entre 1520 y 1611 .

Del recuento y clasificación de dichos ejemplares, según el catálogo de la subasta de su biblioteca, se puede colegir que los libros de Funguerio se corresponden con el perfil de un humanista reformado: su interés por la Sagrada Escritura (15 títulos) y los Padres de la Iglesia y escritores cristianos antiguos (31 títulos de 24 autores), el volumen de libros de autores reformados (115 títulos de 62 autores) y su menor interés por los de ámbito medieval (10 títulos de 9 autores) y católicos coetáneos (38 títulos de 32 autores), resultan reveladores sobre su identidad cultural y religiosa.

\section{Tabla 2}

\begin{tabular}{|c|c|c|c|c|}
\hline $\begin{array}{c}\text { Biblioteca } \\
\text { teológica }\end{array}$ & $\begin{array}{c}\text { Número de } \\
\text { Autores }\end{array}$ & Porcentaje & $\begin{array}{c}\text { Número de tí- } \\
\text { tulos }\end{array}$ & Porcentaje \\
\hline $\begin{array}{c}\text { Sagrada Es- } \\
\text { critura }\end{array}$ & $15^{28}$ & 10,41 & 15 & 7,21 \\
\hline $\begin{array}{c}\text { Padres de la } \\
\text { Iglesia }\end{array}$ & 23 & 15,97 & 31 & 14,90 \\
\hline $\begin{array}{c}\text { Autores me- } \\
\text { dievales }\end{array}$ & 9 & 6,25 & 9 & 4,32 \\
\hline $\begin{array}{l}\text { Autores mo- } \\
\text { dernos católi- } \\
\text { cos }\end{array}$ & 32 & 21,52 & 38 & 18,26 \\
\hline $\begin{array}{c}\text { Autores mo- } \\
\text { dernos refor- } \\
\text { mados }\end{array}$ & 62 & 45,83 & 115 & 55,28 \\
\hline Totales & 141 & 100 & 208 & 100 \\
\hline
\end{tabular}

En cuanto a la temática, para poder delimitar el peso específico de cada disciplina en la biblioteca teológica fungueriana, se ha aplicado el criterio de la división departamental de las Facultades de Teología actuales, en orden a una mayor comprensión y claridad ${ }^{29}$. El resultado, teniendo en cuenta el argumento de los 208 títulos, es el siguiente: Dogmática (43,50\%); Bíblica (32,46\%);

28 En este caso, se trata de ediciones distintas.

29 Se ha utilizado una combinación de la organización interna de las Facultades de Teología de San Dámaso (Madrid), Navarra (Pamplona) y Comillas (Madrid), de acuerdo con sus respectivas páginas web. 
Sacramental y liturgia (10,38\%); Historia de la Iglesia (7,79\%); Moral y espiritual $(5,84 \%)$. Además, se ha podido comprobar que el $24,02 \%$ del total los libros teológicos analizados poseen un claro carácter de controversia o diatriba, propio de la efervescencia doctrinal de la época.

Respecto a la plaza de edición de los libros teológicos, los datos son los siguientes: en la Confederación Suiza se editaron 69: Basilea (37) Ginebra (25) Zürich (5) Lausana (2); 68 corresponden al Imperio Germánico: Colonia (20) Wittemberg (12) Frankfurt (6) Nassau (4) Neustadt (4) Endem (3) Nüremberg (3) Hannover (3) Mainz (3) Leipzig (2) Tubinga (2) Estrasburgo (1) Göttingen (1) Heidelberg (1) Ingoslstadt (1) Marburg (1) Regensburg (1); en los Países Bajos se imprimieron un total de 45: Amberes (16) Leiden (13) Franeker (8) Lovaina (4) Dordrecht (2) Gröningen (1) Haarlem (1). De las prensas francesas salieron 23 libros: París (17) Lyon (5) La Rochelle (1). En otras plazas, cuatro títulos: Londres (2) Nápoles (2) Lisboa (1).

Inicialmente, la plaza de impresión no aporta datos concluyentes sobre el contenido, la confesión religiosa de los compradores o de los editores de libros teológicos, puesto que, como se ha indicado, de la mayoría de las prensas centroeuropeas, al menos desde 1520, fecha de la excomunión de Lutero, salían libros tanto de autores católicos como reformados; es el caso de Amberes, París o Lyon. Otras ciudades, en cambio, como las de la Confederación Suiza desde 1530, publican un notable porcentaje de libros de autores reformados, cercanos a Zwinglio y Calvino. Por regla general, cuanto más tardía sea la impresión y más septentrional sea la plaza de edición, es más probable que se trate de libros no católicos; es el caso de Leiden, Franeker, Endem, Dordrecht, o Estrasburgo, ciudades vinculadas a la reforma calvinista hacia 1540. Otras plazas como Colonia, Lovaina, Ingoslstadt, Nápoles o Lisboa, publicaron de modo habitual, textos de autores católicos.

El estudio de los impresores más frecuentes y de las plazas con mayor número de volúmenes editados de temática teológica, pertenecientes a la biblioteca fungueriana, puede aportar conclusiones parciales, pero no desdeñables. Recopilando los datos, sabemos que de nueve talleres de Amberes, Basilea y Ginebra salieron treinta y siete títulos, es decir, el 19\% del total de la biblioteca teológica del humanista neerlandés. Veamos quiénes fueron los titulares de dichas prensas: de Amberes se cuentan trece títulos realizados por Christophorus Plantinus y ex officina Plantiniana; tres en el taller de su yerno Ioannes Moretus y otros tres en las prensas de Ioannes Steelsius. Desde Basilea llegaron cinco libros de Ioannes Frobenius y ex officina Frobeniana, tres de Ioannes Oporinus y el mismo número de Ioannes Hervagius. De la vecina Ginebra, adquirió cinco 
volúmenes editados por Eustaquius Vignon y dos de Henricus Stefanus y Robertus Stefanus. Veamos algunos datos sobre ellos.

Entre los libros procedentes de los talleres de Plantino (1520-1585) que guardaba el humanista en su biblioteca había tanto volúmenes de Padres de la Iglesia, como obras de reformados, como Calvino o Gomarus, incluidos en el Índice de Sandoval y Rojas de $1612^{30}$.Del librero Steelsius, activo en Amberes entre 1533 y 1562, poseía la Biblia anotada de 1537, impresa junto a Grapheus, de la que Funguerio tenía un ejemplar ${ }^{31}$. Cinco son las obras impresas en Basilea por Froben (1460-1527) y ex officina Frobeniana que adquirió Juan Funguerio: dos son de Padres de la Iglesia y las restantes del príncipe de los humanistas, todas ellas censuradas o expurgadas ${ }^{32}$. Del taller regentado por Oporinus (15071568) en Basilea, adquirió libros de autores reformados como Wolphgang Wyssenburg, Matías Flacius o Andreas Hyperius, pero también de católicos como Regnerus Praedinius. Hervagius (ca. 1497 - 1559) publicó obras de Lutero y otros autores reformados, pero su reconocida fama se debe a la publicación de Padres de la Iglesia y otros escritores antiguos, que suscitaron el interés de nuestro humanista. De Vignon (1530-1559), impresor de confianza de Teodoro Beza, consiguió un volumen sobre los mártires cristianos reformados, ajusticiados por los papistas. Robertus Stefanus o Estienne (1503-1559) alcanzó la fama por sus ediciones de la Biblia hebrea, versiones de la Vulgata y del Nuevo Testamento en griego. Fue censurado por algunos teólogos de Lovaina y París, por lo que decidió trasladarse a Ginebra en 1550, donde publicó una Biblia en francés y el Nuevo Testamento de Beza, del que tenía un ejemplar Juan Funguerio ${ }^{33}$.

30 Bernardo de Sandoval y Rojas, Index librorum prohibitorum et expurgatorum (Matriti, apud Ludovicum Sanchez, 1612). Hemos tomado esta edición como referencia por ser la vigente en los territorios hispanos en la fecha del fallecimiento de Juan Funguerio.

31 Anne Rouzet, Dictionnaire des imprimeurs, libraires et éditeurs belges des XVe et XVIe siècles dans les limites géographiques de la Belgique actuelle, (Bruxelles, Nieuwkoop, 1975) 207-208 y Jesús Martínez de Bujanda (dir.), Index de l'Université de Louvain, 1546, 1550, 1558, Vol. 2, (Paris: Droz, 1986) ,110.

32 Arturo Torres García, “Cuándo, cómo y por qué fue censurado Erasmo”, en Javier Vergara Ciordia-Alicia Sala Villaverde (Coords.), Censura y libros en la Edad Moderna, (Madrid: Dykinson, 2017), 173-232.

33 Elizabeth Armstrong. Robert Estienne, Royal Printer: An Historical Study of the Elder Stephanus. (Cambridge: Cambridge University Press, 2011). 


\section{ANÁLISIS CUALITATIVO DE LA BIBLIOTECA TEOLÓGICA FUNGUERIANA}

\subsection{Ejemplares de la Sagrada Escritura.}

Quince de los libros teológicos eran ejemplares de la Sagrada Escritura. Efectivamente, antes de morir, el humanista tenía en su haber, seis Biblias completas, un Antiguo Testamento y seis versiones del Nuevo Testamento, datados

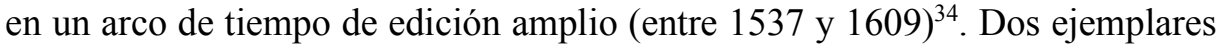
de Biblias completas destacan entre las demás, tanto por su calidad bibliográfica, como por su recepción posterior. Nos referimos a la versión de Santes Pagnino, revisada por Arias Montano y a la Biblia Regia de Amberes, dirigida por el citado hebraísta hispano.

El dominico italiano Sanctes Pagnino (1470-1541) dedicó veinticinco años de su vida a la versión latina interlineal del texto bíblico; fue un proyecto alentado por el Papa León X, que le nombró docente de lenguas orientales; se trata de una traducción palabra a palabra, por tanto, literal en exceso y poco elegante, desde el griego original, cuya primera edición fue impresa en Lyon y data de 1527. Otra de sus novedades fue la división de los capítulos en versículos numerados y la introducción de un notable aparato crítico. Fue una versión muy apreciada tanto por católicos como por reformados, entre los primeros, por Arias Montano; entre los segundos, por Casiodoro de la Reina y Miguel Servet.

Respecto a la Biblia Regia, inicialmente, se suponía que debía ser una segunda edición de la Políglota Complutense, impresa entre 1514-1520, de la que habían desaparecido numerosos ejemplares en un naufragio; pero la versión de Amberes se convirtió en otro proyecto intelectual de gran calado, relevante en sí mismo, que fue apoyado por Felipe II. De la Complutense se tomaron el texto hebreo y el griego de la versión de los Setenta para el Antiguo Testamento. Se incluyó el Tárgum arameo y la versión siriaca del Nuevo Testamento. El grupo de traductores trabajó además con la versión interlineal del erudito Sanctes Pagnino. La traducción fue realizada por Arias Montano (1527-1598), con la colaboración de un amplio equipo de expertos en los Países Bajos. Se imprimieron 1213 ejemplares de los ocho volúmenes que integraban la Biblia completa.

Además de las versiones de Pagnino y Arias Montano, Juan Funguerio también tuvo en su biblioteca personal ediciones bíblicas incluidas en los Índices de libros prohibidos de Lovaina, Roma y territorios hispanos (editadas por

34 Comella-Gutiérrez, "La Sagrada Escritura en la biblioteca de Juan Funguerio (1546-1612), ...", $375-403$. 
Steelsius, Hervagius y Tornaesius). También poseía dos Biblias en lenguas vernáculas (neerlandés y francés) claro signo de su asimilación a posturas reformadas. Respecto a las versiones del Nuevo Testamento, las de su propiedad fueron realizadas por autores o editores controvertidos (Valla, Erasmo, Henri Estienn) o cercanos a la reforma (Rouillé y Oporinus). Debe tenerse en cuenta, según se indicó más arriba, que el 32,46\% de los libros teológicos de la biblioteca fungueriana eran estudios bíblicos, una opción muy acorde en primer lugar, con la formación académica de su dueño en el Colegio Trilingüe de Lovaina en sus años mozos y, en segundo lugar, con el interés en la Biblia propio del humanismo cristiano.

\subsection{Obras de Padres de la Iglesia}

Para los amantes de los studia humanitatis, el acercamiento renovado a la Sagrada Escritura y a las obras de los Padres de la Iglesia, fue el resultado de una notable redditio ad fontes. El afán filológico por localizar manuscritos antiguos de los textos bíblicos, para eliminar las adherencias y erratas de los copistas medievales, se vio respaldado por la difusión de la imprenta, que minimizaba las incorrecciones. Además, los humanistas vieron en los Padres de la Iglesia el culmen de la letras griegas y latinas, un ejemplo de acribia filológica y de inculturación entre la civilización grecorromana y cristiana, dando lugar a la vetus theologia que, durante el Renacimiento, intentó volver a su prístino esplendor.

Juan Funguerio no fue ajeno a estos ideales; se aprecia en su biblioteca una extensa representación de Padres de la Iglesia y autores cristianos, todos ellos anteriores a los cismas de Oriente y Occidente y, por tanto, aceptados por cristianos de cualquier rito y confesión, también después de la reformas protestante y católica ${ }^{35}$. La mayoría son teólogos de primera fila como san Ambrosio, san Agustín, san Beda Venerable, san Cipriano de Cartago, Cirilo de Alejandría, Eusebio de Cesarea, san Gregorio de Nisa, san Hilario de Poitiers, san Ignacio de Antioquía, san Jerónimo, san Justino, Lactancio y Tertuliano. Las obras de dichos autores de la biblioteca fungueriana son respectivamente: el Comentario a la epístola a los Hebreos de san Ambrosio; Comentarios a los Evangelios, Las Confesiones, Los Soliloquios y La Ciudad de Dios (la última en francés) de san Agustín; Obras completas de Beda Venerable en ocho volúmenes; Obras completas de san Cipriano de Cartago; Comentarios a los Evangelios de Cirilo de Alejandría; Historia eclesiástica y Sobre la preparación evangélica de Eusebio

Todos ellos en versión latina, si no se indica otra cosa. 
de Cesarea; Discurso sobre el Espiritu Santo y Sobre la formación del hombre de san Gregorio de Nisa; Obras completas de san Hilario de Poitiers; Epistolas de san Ignacio de Antioquía; Cartas de san Jerónimo; Obras de san Justino mártir; Canto sobre la Pasión y Resurrección de Lactancio y Obras de Tertuliano.

Otros, como Abdías de Babilonia, Arnobio de Sicca, Epifanio de Salamis, Macario de Egipto, Nonnus de Panopolis, Primasius de Hadrumeto, Sulpicio Severo y Teodoreto de Cirene son menos conocidos, aunque vivieron antes del siglo VIII: algunos son considerados apócrifos, polemistas o no siempre mantuvieron la ortodoxia, algo no infrecuente en una etapa que se estaba desarrollando y asentando el dogma católico ${ }^{36}$.

\subsection{Obras de autores medievales}

Los libros de autores medievales de la biblioteca fungueriana son muy escasos, como corresponde al gusto de los humanistas y, especialmente, a los del Norte de Europa, por considerar su latín decadente y sus argumentos redundantes. Veamos quienes son los escritores que Juan Funguerio seleccionó y el argumento de sus libros ${ }^{37}$. Hay libros de Ambrosius Aupertus, abad benedictino de Benevento del siglo VIII, autor de un comentario al Apocalipsis; Bertarius Cassinensis, abad benedictino de Monte Casino del siglo IX, que escribió sobre fragmentos de difícil interpretación del Antiguo Testamento; Honorius Augustodunensis (1080-1153) teólogo, historiador y geógrafo, conocido por su Imago mundi; Johannes Gorus (1260-1333) dominico italiano responsable de una Summa sobre cuestiones teológicas; el Policratus de Juan de Salisbury (11201180) según el cual, el poder temporal deriva del papal y las leyes civiles lo son en cuanto justas y equitativas; Lanfranc de Canterbury, abad de Bec (10051089) autor de un tratado sobre la Eucaristía publicado frente a los errores de Berengario de Tours; Richard Rolle (1300-1349) ermitaño británico autor de un Comentario a los salmos; y una Summa Theologica completa de Tomás de Aquino, editada en 1604.

Sobre esta breve nómina de autores medievales es posible aportar una eventual explicación acerca del interés de Funguerio en ellos. El humanista neerlandés, ex alumno del Colegio Trilingüe de Lovaina, mostró un notable aprecio por algunos comentaristas medievales de la Sagrada Escritura (Aupertus, Bertarius,

36 Jacques-Paul Migne, Patrología latina y griega, en versión electrónica: http://pld.chadwyck.co. uk/ y http://patristica.net/graeca/ (consultada 17-5-2021).

37 Se citarán por orden alfabético, no cronológico. 
Rolle); también incluyó en su biblioteca obras de Honorius Augustodunensis y Salisbury sobre cuestiones interpretativas de la historia y el poder político, cercanas a los intereses del humanismo cívico renacentista, aunque difirieran en sus planteamientos; por último, tres Summas o tratados teológicos (Gorus, Lanfranc y Aquino), consideramos destacables los dos últimos por motivos distintos: en primer lugar, el abad de Bec escribió sobre la primera diatriba teológica sobre la fe en la Eucaristía promovida por su coetáneo Berengario de Tours (999-1088), una cuestión reabierta por Lutero y otros reformados. En segundo lugar, llama la atención que Funguerio adquiriera una Summa Theologica publicada en 1604, cuando él ya se había adherido al calvinismo moderado. Quizá revele precisamente que Juan Funguerio fue un humanista reformado abierto.

\subsection{Obras de autores modernos católicos}

Tras estudiar sus títulos es posible agrupar a los treinta y dos autores en cuatro secciones: religiosos, eclesiásticos, profesores y polemistas. En el primer grupo, que es el más numeroso, se cuentan quince escritores pertenecientes a diversas órdenes y congregaciones religiosas: por ejemplo, Joachim Perion y Franciscus Negri, benedictinos; Agustinus Steuchus, canónigo regular de San Agustín; el agustino Girolamo Seripando y Estanislao Hosio, cardenal polaco, ambos participantes en el Concilio de Trento; los franciscanos Sixto de Siena, Angelo di Chivasso, Pietro Colonna, Johann Ferus y Guillaume de la Mar; el dominico Bartolomé de Carranza; los jesuitas Gregorio de Valencia, Petrus Thyraeus, Tomás Sánchez y Franciscus Costerus.

Hay también seis eclesiásticos de alto rango o bien relacionados con las altas esferas como: Johann Gropper, cardenal alemán, Bartolomé de Carranza, arzobispo de Toledo; Jerónimo Osio Fonseca, arzobispo portugués; Tommasso Campeggi, doctor en ambos derechos, persona de confianza de Adriano de Utrecht; Felipe Beroaldo, responsable de la Biblioteca Vaticana; Gonzalo de la Cerda, predicador de Felipe II.

Entre los once profesores se encuentran: el biblista Seraphinus Cumiranus; Franciscus Lucas de Bruges y Gerard Mercator, conocidos por sus trabajos de exégesis; el teólogo Vitus Miletus; Georg Witzel, musicólogo y liturgista; el matemático Jerónimo Cardano; Josse Ravesteyn, rector de la Universidad de Lovaina; Laurens Beyerlinck, profesor de seminario; Petrus Suffridus y Reinier Veldman, docentes nacidos en Frisia. En el grupo de los polemistas, se puede destacar a Cornelius Schulting, que dedicó parte de sus obras a rebatir el calvinismo y Tilmann Bredenbach, apologista alemán. 
Los treinta y dos escritores católicos citados son autores de un total de treinta y ocho títulos. Con estos datos en la mano, no se puede sacar conclusiones sobre si el humanista Funguerio tuvo mayor interés por algún autor católico de su librería, pero sí sabemos que poseía dos títulos distintos de dos escritores papistas: del neerlandés Cornelio Schulting (1540-1604), canónigo de la catedral de Colonia, en cuya Universidad estudió; autor de veintiséis obras, algunas de marcado contenido anticalvinista ${ }^{38}$ y del jesuita belga Franciscus Costerus (1532-1619) profesor de la misma alma mater, prolífico escritor y polemista frente al luterano Osiander y al calvinista Gomarus ${ }^{39}$.

Analizando el contenido de los libros escritos por católicos, podemos afirmar que el $51 \%$ se refieren a las Sagradas Escrituras y a disputas teológicas contra las doctrinas reformadas. Muestran, por tanto, las inquietudes del humanista Juan Funguerio y las diatribas que llenaron los púlpitos, las cátedras universitarias y las imprentas europeas.

\subsection{Obras de autores modernos reformados.}

En este apartado se reúnen sesenta y dos autores. Unos son considerados antecesores de la reforma protestante en sentido amplio, como es el caso de Erasmo, Wessel Gansfort o Jacques Lefèvre Étaples; otros, son las cabezas visibles de las diversas confesiones cristianas, como Bullinger, Melanchthon, Calvino, Drusius, Gomarus o Whitaker y, de algunos, se conoce su vinculación más o menos estrecha con las nuevas ideas teológicas que modificaron el mapa de Europa.

Así como en el caso de los autores católicos se ha procedido a una agrupación en cuatro clases (religiosos, jerarquía, profesores y polemistas), consideramos que no es posible aplicar esta clasificación completa a los reformados; por tanto, procedemos a asignarles otro criterio metodológico para buscar puntos comunes en este otro amplio grupo de escritores. Hemos optado por dividirlos de acuerdo con su filiación religiosa concreta (luteranos, helvéticos, calvinistas y grupos derivados, anglicanos y puritanos), porque consideramos que este dato

38 Carter Lindberg, The Reformation Theologians: An Introduction to Theology in the Early Modern Period, (Malden, Blackwell, 2017) 209. Una bibliografía completa puede consultarse en línea: https://www.deutsche-digitale-bibliothek.de/person/gnd/124778011?lang=en

39 Gijsbert van den Brink - Harro Höpfl, Calvinism and the Making of the European Mind (Leiden: Brill, 2014) 143-146. Sobre Gomarus y su obra: https://www.dbnl.org/auteurs/auteur.php?id=cost012 
es sumamente significativo para conocer las lecturas del humanista Juan Funguerio.

Luteranos (22 autores): Amandus Polanus, Andreas Hyperius, Christoph Herdesianus, Felipe Melanchthon, Esteban Kiss, Joachim Beringer Ursinus, Jodocus Nahumius, Johannes Brenz, Johannes Gastius, Konrad Platz, Victorinus Strigel, Lucas Lossius, Johannes Lonicer, Johannes Posselio, Johannes Sturm, Matías Flacius, Gerardus Mathisius, Petrus Palladius, Johan Spangenberg, Rudolf Goclenius, Sebastian Münster, Theophilus Cangiserus, Valentin Schindler, Ulrich von Hutten.

Helvéticos $^{40}$ : (6 autores) Benedictus Aretius, Enrique Bullinger, Joachim Vadianus, Rudolf Gwalther, Thomas Erastus, Wolfgang Wyeissenburger.

Calvinistas (20 autores): Abraham Scultetus, Antoine de la Faye, Claude Baduel, Gellius Snecanus, Juan Calvino, Franciscus Junius, Teodoro Beza, George Buchanan, Hadrian Saravia, David Chytraeus, Daniel Chamier, Lambert Daneau, Jacobus Brocardus, Johannes Acronius, Franciscus Balduinus, Philippe Duplessis-Mornay, Johannes Piscator, Johannes Sturm, Felipe de Mornay, Zacharias Ursinus.

Calvinistas-Arminianos (2 autores): Johannes Drusius y Conrad Vorstius ${ }^{41}$.

Calvinistas-Gomaristas (3 autores): Francisco Gomarus, Johannes Polyander y Sibrandus Lubbertus.

Anglicanos (3 autores): Anthony Champney, Thomas Cranmer, Matthew Sutcliffe

Puritanos (3 autores): William Whitaker, William Perkins y John Rainolds.

De los sesenta y dos autores precursores de la reforma protestante y reformados, Juan Funguerio poseía un total de ciento quince obras. Los escritores

40 Denominamos "helvéticos" a los seguidores del Zwinglio, que predicaron con éxito en Frisia occidental a partir de 1530 .

41 Jacobo Arminio (1560-1609) estudió Teología en Leiden con Drusius, Danaeus y Kolmann (este último calvinista estricto); posteriormente se trasladó a Ginebra bajo el magisterio de Teodoro Beza y fue ordenado pastor en 1588, destinado a Amsterdam. Sin embargo, se fue apartando de los llamados Cinco puntos del Calvinismo, especialmente en lo referido a la predestinación, contando con el apoyo de su maestro Johannes Drusius. Ambos se mostraron favorables a la tolerancia con otros grupos cristianos, como los menonitas de los Países Bajos. Por su parte, Francisco Gomarus (1563-1641) se opuso radicalmente a los arminianos, a los que tachaba de pelagianos, mientras éstos le consideraban maniqueo. Tanto Mauricio de Nassau, jefe político de las Provincias del Norte independizadas de Felipe II, como los Estados Generales mantuvieron su apoyo al calvinismo estricto a través del Sínodo de Dort (1618-1619). Selderhuis (ed.), Handbook of Dutch Chruch History... 53-56. 
con mayor número de títulos son los siguientes: Erasmo (4), los calvinistas Drusius (8), Calvino (5), Beza (5) y Saravia (2); los luteranos Melanchthon (4) y Chytraeus (4), el helvético Bullinger (4) y los puritanos Whitaker y Rainolds (3). Veamos con cierto detalle de qué obras se trataba.

Todos los escritos erasmianos que conservaba Juan Funguerio procedían ex officina frobeniana y eran mayoritariamente comentarios a textos novotestamentarios (Evangelios, Hechos de los Apóstoles y Epístolas), a excepción de un tratado de retórica aplicado a la predicación (De ratione concionandi). Otra salvedad, respecto al impresor, es una edición erasmiana de su versión latina del Nuevo Testamento, procedente del taller de Franciscus Gryphius de Leiden, fechado en $1553^{42}$.

Es notable el caso de Johannes Clementis Drusius (Jan van den Driesche) (1550-1616), nacido en Flandes en el seno de una familia pudiente y reformada; estudió lenguas clásicas en Gante y Lovaina. Se exilió en Inglaterra por motivos religiosos durante unos años y llegó a ser un notable hebraísta. Fue profesor de lenguas orientales en Oxford y, tras la Pacificación de Gante, volvió a su tierra natal, siendo contratado como profesor de hebreo en la Universidad de Leiden. Allí fue alumno suyo Jacobo Arminio y ambos participaban de las mismas ideas religiosas, centradas en un calvinismo moderado y tolerante. Desde 1585 pasó a dar clases en la Universidad de Franeker (Frisia); en 1600, los Estados Generales le encargaron la traducción al neerlandés de pasajes oscuros del Antiguo Testamento, tarea que le llevó el resto de su vida. Es muy posible que Drusius y Funguerio se conocieran en Franeker, donde el segundo vivió entre 1607 y 1612, durante su último destino como rector de la escuela de gramática de dicha población. Si no fue así, al menos tuvo en alta estima sus obras, dedicadas íntegramente a la exégesis bíblica, puesto que tenía en su biblioteca ocho títulos, publicados entre 1585 y 1591 , pergeñados por la mente preclara de Drusius ${ }^{43}$.

Las obras de Calvino y Beza pertenecientes a la biblioteca fungueriana poseen un doble cariz: la mayoría poseen carácter exegético, es decir, son comentarios a libros de la Sagrada Escritura y, el resto, recogen controversias teológicas de la época. Cabe destacar el interés de nuestro humanista por la polémica abierta entre Calvino y Beza contra Franciscus Balduinus (1520-1573). Jurista

42 Miguel Anxo Peña González - Inmaculada Delgado Jara (coords.), Revolución en el humanismo cristiano: La edición de Erasmo del Nuevo Testamento, (1516), (Salamanca: Publicaciones de la Universidad de Salamanca, 2016), 245-277.

43 Lionel North, "Jan van den Driessche (Johannes Drusius) 1550-1616 and the Study of the Old Testament in the New", en The Scriptures of Israel in Jewish and Christian Tradition, (Leiden: Brill, 2013): 409 - 423. https://doi.org/10.1163/9789004247727_028 
e historiador nacido en Arrás y formado en la Universidad de Lovaina, fue consejero de Carlos $\mathrm{V}$ y se pasó a la confesión calvinista en 1545. Sus viajes y contactos en Europa le llevaron a reflexionar sobre la situación religiosa y participó activamente en el Coloquio de Poissy (1561), donde se intentó sin éxito limar diferencias entre los católicos y hugonotes franceses. Después, Balduinus se enfrentó por escrito a Calvino y, posteriormente, a su sucesor Teodoro Beza; reconsideró sus convicciones y volvió al seno del catolicismo en $1563^{44}$.

Otro autor calvinista frecuente en la biblioteca teológica fungueriana fue Hadrian Saravia (1532-1612), franciscano de origen belga, que abrazó la reforma en 1557 y colaboró en la redacción de la Confessio belga (1561), una de las bases teóricas del calvinismo. Fue profesor en la Universidad de Leiden, pero se vio obligado a huir a Inglaterra por motivos políticos. Allí percibió prebendas eclesiásticas y participó en la traducción de la Biblia del Rey Jaime, publicada en 1611, versión oficial para la iglesia anglicana y pieza notable de la cultura inglesa $^{45}$. Dos son las obras de Saravia propiedad de Funguerio: un tratado sobre los ministros del Evangelio y otro sobre los sacrilegios y sus penas.

Resulta un tanto insólito que en la biblioteca fungueriana no se encuentre ningún libro de Martín Lutero y, sin embargo, fuera dueño de varias obras de Felipe Melanchthon (1497-1540), uno de sus principales colaboradores, de talante más moderado y conciliador, que redactó la Confesión de Ausburgo y procuró no romper el diálogo con los católicos. En los anaqueles de su casa, el humanista de Frisia guardaba un comentario suyo a la Epístola a los Colosenses, dos volúmenes de su opera omnia y un ejemplar de sus Loci theologici, texto que sintetizaba el contenido de la teología luterana, apoyándose en la Biblia y en los Padres de la Iglesia ${ }^{46}$.

Juan Funguerio, según parece, siguió con interés a otro autor luterano de origen germano llamado David Chythareus (1530-1600). Fue profesor de la Universidad de Rostock, redactor de un catecismo y de la Fórmula de la Concordia (1577), formada por un resumen en doce capítulos de la fe luterana ${ }^{47}$. Sin embargo, los títulos de este autor que guardó en su biblioteca fueron dos

44 Agostino Di Bondeno, Colloqui di Poissy, (Roma: Albatros, 2018) 56-69.

45 Puede consultarse en línea: https://www.kingjamesbibleonline.org/1611-Bible/

46 Juan Luis Monreal Pérez, "La contribución de Philipp Melanchthon, praeceptor Germaniae, a la lengua y a la enseñanza. Entre la cultura humanista europea y la reforma alemana", en Historia de la Educación. Revista Interuniversitaria, 36 (2017) 207-228.

47 Puede consultarse en línea: https://bookofconcord.org/formula-of-concord-epitome/ 
comentarios de carácter exegético, un discurso sobre el estado de la iglesia y una respuesta a las acusaciones formuladas por el jesuita Antonio Possevino ${ }^{48}$.

También interesó a Funguerio la obra de Bullinger (1504-1575), sucesor de Zwinglio en la reforma en Suiza, sintetizada en las Confesiones Helvéticas de 1536 y 1566, más cercanas al calvinismo que al luteranismo y el anabaptismo. Entre sus obras presentes en la biblioteca de Juan Funguerio se encuentran: una historia de la iglesia en Zürich, un sermón sobre la cena del Señor (uno de los motivos de fricción con los luteranos), un tratado sobre lugares teológicos y un escrito contra los anabaptistas de Menno Simons ${ }^{49}$.

Dos fueron los teólogos puritanos británicos cuya lectura llamó la atención de Juan Funguerio: William Whitaker (1548-1594) y John Rainolds (15481607). Del primero pudo leer una disputa con los papistas sobre la Sagrada Escritura; una polémica sobre los Concilios y Papas contra Roberto Bellarmino; además de un comentario a los sermones de John Allenson, su principal discípulo. Del segundo, tuvo a la mano una controversia sobre la idolatría en la Iglesia romana, cuestión de la que los puritanos, con su afán de purificar la liturgia de imágenes y apoyos externos, lucharon con denuedo.

\section{ANÁLISIS HERMENÉUTICO DE LA BIBLIOTECA TEOLÓGICA FUNGUERIANA}

Llegados a este punto, cabe preguntarse si los libros teológicos de la biblioteca de Juan Funguerio reflejan su trayectoria vital, su personalidad, sus opciones religiosas, y el contexto en el que vivió. La respuesta es afirmativa. Veamos las razones.

En primer lugar, cabe recordar que el humanista de Leeuwarden se formó en la escuela de gramática latina de su padre y estudió en el Colegio Trilingüe de Lovaina: estas circunstancias marcaron fuertemente su amor por las lenguas clásicas y bíblicas, que se manifestó en la adquisición o conservación de 67 títulos relativos a la Sagrada Escritura (32,46\% del total de libros teológicos). Era dueño de quince volúmenes de la Biblia o sus libros: dos valiosas versiones del texto completo realizadas por Santes Pagnino y Arias Montano en el ámbito católico y de otras traducciones próximas a autores controvertidos como Valla, Erasmo y Estienn, o bien, directamente incluidas en los Índices de libros prohibidos de Lovaina, Roma y territorios hispanos (editadas por Steelsius,

48 Luigi Balsamo, "Il gesuita Antonio Possevino, un eroe del suo tempo", Bibliofilia, 113 (2011): 211-223.

49 Wenceslao Calvo, Historia de la Iglesia evangélica,... 357. 
Hervagius y Tornaesius). También poseía dos Biblias en lenguas vernáculas (neerlandés y francés) claro signo de su asimilación a posturas reformadas.

En segundo lugar, Funguerio supo apreciar, la acribia filológica y la inculturación en el universo grecorromano propia de los Padres de la Iglesia y de otros escritores cristianos anteriores al siglo VIII. Para los humanistas, a estos autores se debe gran aprecio por ser artífices de la vetus theologia, es decir, de un acercamiento a la ciencia sobre Dios, basado en la Sagrada Escritura y en la filosofía clásica. Todos los títulos de esta etapa están en lengua latina, aunque se trate de autores que escribieron originalmente en griego $u$ otras lenguas orientales. De los veintitrés autores de la Patrística, el más frecuente en los anaqueles de la biblioteca fungueriana fue san Agustín, con cinco tomos de sus obras completas y un comentario a los Evangelios.

En tercer lugar, el humanista neerlandés hizo gala de escaso aprecio hacia los autores medievales, como era habitual entre sus coetáneos. Muchos se habían formado en universidades que seguían métodos propios de la escolástica tardía y utilizaban un latín decadente, lejos de los modelos clásicos que Italia había recuperado para Europa desde el siglo XIV. Los libros medievales de la biblioteca fungueriana alcanzaban el 4,32\% de los títulos teológicos y, entre ellos, destacan dos autores notables: Juan de Salisbury y Tomás de Aquino. El Policratus de Salisbury es un volumen de interés para un humanista doctor en ambos derechos como Funguerio, familiarizado con cuestiones relativas a la conjunción entre el poder espiritual eclesiástico y el poder terrenal político. Respecto a la Summa Theologica del doctor Angélico de su propiedad, como se ha indicado, la edición es de 1604 y no estamos en condiciones de aportar una posible explicación, si bien, es un autor representante de la mejor Escolástica.

En cuarto lugar, en la biblioteca teológica fungueriana se encuentran únicamente treinta y dos autores coetáneos católicos, que se ha agrupado en cuatro categorías: religiosos, eclesiásticos, profesores y polemistas. Entre los primeros, destacan en número los franciscanos y jesuitas; entre los segundos, Tomasso Campeggi, mano derecha del papa Adriano VI, de origen neerlandés, ex alumno y rector de Lovaina; varios profesores destacan por sus obras de exégesis, apreciadas por Funguerio, egresado del Colegio Trilingüe; del cuarto grupo, se puede subrayar los títulos de Schulting y Costerus, arietes de la polémica teológica frente a calvinistas puros y gomaristas; cabe recordar que Juan Funguerio era proclive a un calvinismo moderado, cercano a Arminio y que, quizá por ese motivo, le interesaron esas lecturas.

En quinto lugar, cabe aportar luz sobre el significado de las lecturas funguerianas de teólogos coetáneos, tanto cercanos a la reforma (como Erasmo, 
Wessel Gansfort o Jacques Lefèvre Étaples) como reformados: de estos últimos se hallan en las estanterías del humanista de Frisia obras de las principales corrientes cristianas de nuevo cuño que impactaron de lleno, entre 1530 y 1550 , en las Provincias Unidas del norte de los Países Bajos antes de su independencia del rey Felipe II, a saber: luteranos, helvéticos, calvinistas, arminianos y gomaristas. En menor medida, los autores anglicanos y puritanos británicos interesaron a Juan Funguerio. El teólogo con el que parece pudo identificarse más nuestro humanista fue Johannes Drusius, con el que quizá coincidió cuando ambos vivían en la ciudad frisona de Franeker. El hecho de que Funguerio poseyera ocho de sus escritos, puede indicar que compartía sus ideas religiosas, inscritas en el calvinismo moderado y tolerante propio de los arminianos.

\section{CONCLUSIONES}

Para conocer las lecturas teológicas del humanista Juan Funguerio se ha partido de un documento marco: el catálogo de la subasta de su biblioteca, llevada a cabo en Leiden el 22 de mayo de 1613, un año después de su fallecimiento. El enfoque metodológico utilizado en la redacción de estas líneas ha tenido cuatro ejes: el contexto histórico, el mapa estadístico, la tipología cualitativa (editores, plazas de edición, autores) y, finalmente, una posible interpretación explicativa de los resultados obtenidos.

El acercamiento a la biblioteca teológica fungueriana nos remite a las coordenadas culturales, religiosas y políticas en las que vivió el dueño de los libros. Juan Funguerio pertenece a la corriente humanista del norte de Europa: formado en la escuela de gramática latina paterna, estudió en universidades de cuño católico, filología bíblica en Lovaina y ambos Derechos en Colonia, que le aportaron, respectivamente, un profundo amor a la Sagrada Escritura y un sentido de moderación, presentes en su toda su existencia, que dedicó al estudio y a los libros, a la docencia y la escritura.

Fue testigo de la denominada revuelta de Flandes contra Felipe II, señor de los Países Bajos: el levantamiento independentista de las provincias del norte, en las que se habían extendido diversas ramas de la reforma (luteranos, helvéticos, anabaptistas y calvinistas) bajo el liderazgo de Guillermo de Orange, seguidor de los últimos. El hijo de Carlos V rechazaba no solo que hubiera herejes en sus tierras, sino también la posibilidad de perder parte de una región tan rica y geoestratégica como Flandes, que se convirtió en su talón de Aquiles y en el de sus sucesores. 
Juan Funguerio optó por abandonar una eventual brillante carrera como abogado y magistrado en su Frisia natal y ser rector de escuelas de gramática latina, siguiendo la huella de su padre y de su suegro, aunque también para ocupar dicho cargo público pasó a formar parte de una congregación calvinista. Sin embargo, sus aspiraciones en materia religiosa, si se tienen en cuenta sus lecturas teológicas, parecen más cercanas al calvinismo arminiano, de cariz tolerante y moderado.

Llama la atención el volumen de la biblioteca privada que llegó a reunir el humanista de Leeuwarden integrada por 1155 libros, en la que se encontraban cuatro incunables y otras valiosas ediciones. El 18\% del total de títulos, que equivalen a 208, eran de temática teológica y fueron editados entre 1513 y 1611 , es decir, durante una centuria completa, marcada por la eclosión de la imprenta y la difusión de las ideas reformadas, dos hechos intrínsecamente relacionados entre sí. En líneas precedentes, se han apuntado eventuales explicaciones sobre la amplitud del conjunto de esta biblioteca y la incorporación de los títulos a la misma, en cada década de la centuria señalada.

El estudio de los impresores y plaza de edición de esta biblioteca teológica concluye que la mayor parte de sus libros procedían de talleres de la Confederación Helvética, Países Bajos, Imperio Germánico y Francia, siendo habituales las prensas de Amberes, Basilea y Ginebra, donde se publicaron el 19\% de dichos títulos. Aunque de la mayor parte de esos talleres salían tanto libros católicos como reformados, es plausible concluir que, cuanto más septentrional sea la ciudad y más tardía la edición, hay más probabilidad de que estemos ante un autor reformado, dada la expansión de los distintos grupos no católicos a partir de 1520 , fecha de la excomunión de Lutero.

Juan Funguerio poseía un total de quince ejemplares de textos bíblicos; además contaba con obras de treinta y un Padres de la Iglesia o escritores coetáneos, de nueve medievales, de sesenta y dos de reformados coetáneos y de treinta y dos católicos de su época. En su conjunto, las disciplinas abordadas con mayor frecuencia en el argumento de los libros fueron la Teología Dogmática $(43,50 \%)$ y Bíblica $(32,46 \%)$.

Las cuestiones relativas a la fe cristiana aparecen en bastantes ocasiones con carácter polémico o reflejan controversias de la época; además, el $24 \%$ del total de libros teológicos de Funguerio poseen ese sesgo: recogen, por ejemplo, las disputas entre los católicos Schulting y Costerus contra calvinistas y gomaristas; del luterano Chythareus contra el jesuita Possevino; de Calvino y Beza contra Balduinus; del helvético Bullinger contra el anabaptista Simons; de los puritanos Whitaker y Rainolds contra el jesuita Bellarmino. Sin embargo, 
también destacan entre los autores frecuentes y quizá apreciados por el humanista de Leeuwarden, las obras de escritores que hicieron gala, con su pluma y su existencia, de moderación como Melanchthon y Drusius, más cercanos al talante del propio Funguerio.

En lo referente a la Teología bíblica, entre los libros de la biblioteca fungueriana, cabe destacar la Biblia interliniaria de Santes Pagnino y la Regia de Amberes, que aunaban ortodoxia católica y calidad filológica; en cuanto al resto de los libros bíblicos de su propiedad, sabemos que la autoría de los comentarios o sus editores fueron cercanos a posturas reformadas, incluidas traducciones a lenguas vernáculas como francés o neerlandés. Es patente, por tanto, la veneración del ex alumno del Colegio Trilingüe de Lovaina tuvo a la Sagrada Escritura y que, como experto filólogo y humanista de criterio, manejó textos reformados y católicos coetáneos, aunque los primeros doblan en número a los segundos.

\section{REFERENCIAS BIBLIOGRÁFICAS}

Armstrong, Elizabeth. Robert Estienne, Royal Printer: An Historical Study of the Elder Stephanus. Cambridge: Cambridge University Press, 2011.

Balsamo, Luigi. "Il gesuita Antonio Possevino, un eroe del suo tempo", Bibliofilia, 113 (2011): 211-223.

Calvo, Wenceslao. Historia de la Iglesia evangélica. Madrid: Publicaciones de la Iglesia evangélica, 2011.

Cathalogvs Bibliothecae Instructissimae Doctissimi \& Viri D. Ioannis Fungeri, I.V. Doct. \& Gymnasii Franekerani Moderatoris, quae auctione distrahetur in Officina Ioannis Orlers Bibliopolae, in vico de S. Pieters Chom-Steegh. Lvgdvni Batavorvm 22 may. Anno 1613. Stylo Nouo. Excudebat Henricus Ludouici ab Haestens. Biblioteca Nacional de Dinamarca, ms. 79 II 29.

Comella-Gutiérrez, Beatriz. "El humanista neerlandés Juan Funguerio (15461612): de la teoría a la práctica política". En Estudios de educación política, coordinado por Javier Vergara Ciordia-Alicia Sala Villaverde (Madrid: Dykinson, 2019), 251-260.

Comella-Gutiérrez, Beatriz. "Johann Funger's pedagogy in the context of northern humanism", History of Education\& Children's Literature, XIII/1 (2018): 355-374.

Comella-Gutiérrez, Beatriz. "La Sagrada Escritura en la biblioteca de Juan Funguerio (1546-1612), un calvinista neerlandés de primera hora", Anuario de Historia de la Iglesia, 29 (2020): 375-403.

Comella-Gutiérrez, Beatriz. El humanista Juan Funguerio ante la censura". En Censura y libros en la Edad Moderna, coordinador por Javier Vergara Ciordia-Alicia Sala Villaverde (Madrid: Dykinson, 2017), 269 - 281. 
Dadson, Trevor J. Libros, lectores y lecturas, estudios sobre bibliotecas particulares españolas del Siglo de Oro. Madrid: Arco Libros, 1998.

Ebben, Mauricio. El final de la Guerra de Flandes. Madrid: Fundación Carlos de Amberes, 1998.

Engels, Martin H. Chronologische en alfabetische naamlijst 1577-1849. Leeuwarden: Fryske Akademy, 2016.

Funguerio, Juan. Libro sobre la buena enseñanza y educación de los jóvenes (1584) De puerorum disciplina et recta educatione liber. Editado por Beatriz Comella-Gutiérrez, estudio preliminar. Virgilio Rodríguez García, Traducción y notas. Madrid: UNED-BAC, 2018.

Galende Díaz, Juan Carlos. "Las bibliotecas de los humanistas y el Renacimiento", en Revista general de información y documentación, 6 (1996/2).

Grendler, Paul F. Renassaince Education between Religion and Politics. Aldershot: Routledge, 2006.

Lindberg, Carter. The Reformation Theologians: An Introduction to Theology in the Early Modern Period, Malden: Blackwell, 2017.

Lindsay, Thomas Martin. La Reforma y su desarrollo social. Barcelona: Clío, 1986.

Martínez de Bujanda, Jesús. (dir.) Index de l'Université de Louvain, 1546, 1550, 1558, Vol. 2, Paris: Droz, 1986.

McKitterick, David. The Invention of Rare Books: Private Interest and Public Memory (1600-1840), Cambridge: Cambridge University Press, 2018.

Migne, Jacques-Paul. Patrología latina y griega, en versión electrónica: http://pld.chadwyck.co.uk/ y http://patristica.net/graeca/.

Molhuysen, Philipp Ch. - Blok, Petrus J. Nieuw Nederlandschbiografisch woordenboek. Leiden: A.W. Sijthoff, 1918.

Monreal Pérez, Juan Luis. "La contribución de Philipp Melanchthon, praeceptor Germaniae, a la lengua y a la enseñanza. Entre la cultura humanista europea y la reforma alemana", en Historia de la Educación. Revista Interuniversitaria, 36 (2017) 207-228.

North, Lionel. Jan van den Driessche (Johannes Drusius) 1550-1616 and the Study of the Old Testament in the New. Leiden: Brill, 2013.

Paradinas Fuentes, José Luis. Humanismo y educación en el Dictatum Christianum de Benito Arias Montano. Huelva: Publicaciones de la Universidad de Huelva, 2006.

Peña González, Miguel Anxo - Delgado Jara, Inmaculada (coords.). Revolución en el humanismo cristiano: La edición de Erasmo del Nuevo Testamento, (1516). Salamanca: Publicaciones de la Universidad de Salamanca, 2016.

Rodríguez Moñino, Antonio. La biblioteca de Benito Arias Montano. Noticias y documentos para su reconstrucción (1548-1598). Badajoz: Diputación Provincial de Badajoz, 1929. 
Rouzet, Anne. Dictionnaire des imprimeurs, libraires et éditeurs belges des XVe et XVIe siècles dans les limites géographiques de la Belgique actuelle. Bruxelles: Nieuwkoop, 1975.

Sandoval y Rojas, Bernardo de. Index librorum prohibitorum et expurgatorum. Matriti: apud Ludovicum Sánchez, 1612.

Schepper Marcus de, Bibliographie de l'humanisme des anciens Pays-Bas: avec un répertoire bibliographique des humanistes et poètes néo-latins: supplément 1970-1985. Bruxelles: Koninklijke Academievoor Wetenschappen Letteren en Schone Kunsten van België, 1988.

Sebastiani, Valentina. Johann Froben: Printer of Basel: A Biographical Profile and Catalogue of His Editions. Leiden: Brill, 2018.

Selderhuis, Herman. Handbook of Dutch Chruch History. Göttingen: Vandenhoeck \& Ruprecht Verlage 2014.

Torres García, Arturo. "Cuándo, cómo y por qué fue censurado Erasmo". En Javier Vergara Ciordia-Alicia Sala Villaverde (Coords.), Censura y libros en la Edad Moderna. Madrid: Dykinson, 2017, 173-232.

Van den Brink, Gijsbert - Höpfl, Harro. Calvinism and the Making of the European Mind. Leiden: Brill, 2014.

Vergara Ciordia, Javier, "Las obras pedagógicas del humanismo erasmista" en Peña González, Miguel Anxo - Delgado Jara, Inmaculada (coords.), Revolución en el humanismo cristiano: La edición de Erasmo del Nuevo Testamento (1516), Salamanca, 2016.

Zijlstra, Samme. Het geleerde Friesland studenten ca. 1380-1650, en:

http://files.mpaginae.webnode.com/200000728-b6ac7b7a64/FrieseStudentenvoor1650.pdf

Beatriz Comella-Gutiérrez

Dep. de Historia de la Educación y Educación Comparada

Facultad de Educación

Universidad Nacional de Educación a Distancia - UNED

Calle Juan del Rosal, 14

28040 Madrid (España)

https://orcid.org/0000-0002-4749-7742 